\title{
NOISE ATTENUATION IN SEISMIC REFLECTION DATA COMBINING EMPIRICAL MODE DECOMPOSITION AND SVD FILTERING
}

\author{
Felipe da Mota Alves and Milton J. Porsani
}

\begin{abstract}
Noises are common events in seismic reflection that have very striking features in the seismograms, hindering the data processing and interpretation. The attenuation of seismic noise is a challenge. In general frequency filters are employed, but they often do not show good results. The characteristic of noise depends mainly on the type of data we are working. In land data, the most common is the ground roll, that has low frequencies and high amplitudes whereas in marine data (on a shallow water acquisition), head waves and harmonic modes are linear and dispersive events that mask part of the interest reflections, influencing the delimitation of lithological layers. In this study, we used the methods of Empirical Mode Decomposition (EMD) and Singular Value Decomposition (SVD) in order to mitigate some types of noise in seismic reflection and create alternatives to interpretation based on different frequency content present in seismic section. This new approach consists in relating the operation mode of each method with the main features of the noise, resulting in a technique that can identify and mitigate the unwanted event from the seismograms, trying always to preserve or enhance the interest signal. To test the effectivity of this new approach, were used land seismic data from the Tacutu Basin and marine from the Grane oilfield area, Norway.
\end{abstract}

Keywords: seismic noise, Empirical Mode Decomposition, Singular Value Decomposition.

RESUMO. Ruídos são eventos comuns na sísmica de reflexão que possuem características bem marcantes nos sismogramas, atrapalhando o processamento e a interpretação dos dados. A atenuação de ruídos sísmicos é um desafio. Em geral são utilizados filtros de frequência muitas vezes ineficazes. A característica do ruído depende principalmente do tipo de dado com que estamos trabalhando. Em dados terrestres, o ruído mais comum é 0 ground roll, que apresenta baixas frequências e altas amplitudes, enquanto em dados marinhos, para uma aquisição com lâmina d'água rasa, as head waves e os harmonic modes são eventos lineares e dispersivos que mascaram parte das reflexões de interesse, influenciando na delimitação de camadas litológicas. No presente trabalho foram utilizados os métodos de Decomposição em Modos Empíricos (EMD) e Decomposição em Valores Singulares (SVD) no intuito de atenuar alguns tipos de ruídos em dados sísmicos de reflexão e criar alternativas de interpretação com base nos diferentes conteúdos de frequência presentes na seção sísmica. Essa nova abordagem consiste em relacionar o modo de atuação de cada método com as principais características do ruído, resultando em uma técnica que consegue identificar e atenuar o evento indesejado dos sismogramas, buscando sempre preservar ou intensificar o sinal de interesse. Para testar a eficácia da nova abordagem foram utilizados dados sísmicos terrestres da Bacia do Tacutu e marinhos da região do campo petrolífero de Grane, na Noruega.

Palavras-chave: ruídos sísmicos, Decomposição em Modos Empíricos, Decomposiç̧ão em Valores Singulares.

Universidade Federal da Bahia, Centro de Pesquisa em Geofísica e Geologia/INCT-GP/CNPq, Instituto de Geociências, Campus Universitário da Federação, Salvador, BA, Brazil - E-mails: felipedamotaalves@hotmail.com; porsani@cpgg.ufba.br 


\section{INTRODUCTION}

Seismic reflection is a geophysical method often employed by the hidrocarbons exploration and production industry. It allows obtaining representative images of the subsurface based on the elastic waves propagation in the geological environment. Because it is a relatively inexpensive technique (Telford et al., 1990), which provides good results, their use is growing every day. The seismic activity starts from the field acquisition, through the data processing (Yilmaz, 2001) and ends at the interpretation, stage in which will be flagged potential areas for oil exploration, if this is your initial goal. The data processing is an important step in the seismic section generating, if it is well performed there are high chances of wells allocation being successful. One main reason for that processing does not reach its objectives is the noise presence in seismograms.

Noises are common events in land and marine seismic data, the ground roll is a prime example. It is present in terrestrial data and its existence is related to Rayleigh surface waves propagation. The ground roll is a coherent noise characterized by the high amplitudes, low-frequency, low propagation speed and in a non-homogeneous media is highly dispersive, masking the interest reflection in the seismograms. Marine seismic data tend to be less noisy, but they aren't free of these events. In this paper, we will mainly deal the harmonic modes and head waves that have a linear and dispersive provision in seismograms, in addition to having an extensive range of frequencies, hindering filter performance limited by the noise wavelength. In order to eliminate noises from seismograms various filtering methods were developed, the most known are the bandpass and the f-k. The main limitation of these filters is that, in addition to removing the noise they can act on frequency bands related to the interest reflections. To overcome these difficulties some authors seek new techniques. Melo et al. (2009) presents a filtering method based in 2D directional derivative. In this paper, we propose test different ways of filtering based on modern techniques of signal processing, as Empirical Mode Decomposition (EMD) (Huang et al., 1998; Ferreira, 2010; Sá, 2013) and Singular Value Decomposition (SVD) (Freire, 1986).

There are different works that use the EMD application for signal processing. Zegadi \& Zegadi (2009) and Bekara \& Baan (2009) worked with attenuation of coherent and random noise. Alves et al. (2011) applied EMD technique together with the radial transform (RT) and obtained results in the attenuation of linear noise like the direct and refracted wave and the ground roll. Sá (2013) studied the effects of Intrinsic Mode Functions (IMFs) manipulating in mitigation of seismic noise, com- mon in marine acquisitions like swell noise. The SVD method application in seismic data isn't new. Freire (1986) presented the main technique effects when introduced in the data processing flowchart. Cardoso (2010) and Lima (2014) applied the singular value decomposition in order to mitigate the surface rolling noise.

EMD method consists in decomposing a signal in IMFs having, each one determined frequency band. Its application in seismic data is the rearrangement of each trace in a sum of IMFs with decreasing frequency. The SVD decomposition enables any data matrix to be factored into a finite weighted sum of unitary matrices. In seismic data this method can be used for events separation and filtration, since the events with increased horizontal correlation are preserved in the first eigenimages. The SVD method can be performed in conjunction with the EMD, by making appropriate choice of eigenimages and IMFs, resulting in a set of seismograms with events that have different temporal and spatial characteristics that are of most interest.

\section{EMPIRICAL MODE DECOMPOSITION}

The Empirical Mode Decomposition (EMD) is a signal processing technique developed by Huang et al. (1998) designed to extract as much information as possible about a given signal oscillating behavior. The method EMD assumes that several oscillatory modes composes the same signal, each preserving the characteristic frequency, in their own way, the original data features. Each of these oscillatory modes is represented by an Intrinsic Mode Functions (IMF). Each IMF have the following characteristics:

- The number of zeros and extremes in the data set are equal or differ no more than one;

- They are symmetrical with respect to the average. For any point, the sum of the maximum value of the envelope with minimum envelope is equal zero.

These two conditions ensure that the functions are symmetrical relative to the local average and instantaneous frequency will not have a anomalous behavior that does not preserve original data characteristics.

The process for applying the EMD method is simple and can be divided in three main steps:

1. The seismic trace is mapped and are identified all local extremes (maximum and minimum points);

2. The maximum and minimum points are interpolated obtaining maximum and minimum envelopes. For this step we used the $1 \mathrm{D}$ interpolation subroutine developed based on inverse of the distances (Shepard, 1968); 
3. For each point is calculated the maximum and minimum envelopes average $m$, it is subtracted from the input signal $X(t)$. This result is a candidate for IMF $\Psi_{1}(t)$.

Mathematically, the process can be described by:

$$
\begin{gathered}
m(t)=\frac{e_{\text {sup }}(t)+e_{i n f}(t)}{2}, \\
\Psi_{1}(t)=X(t)-m(t) .
\end{gathered}
$$

To be considered an IMF, $\Psi_{1}(t)$ must satisfy previously presented conditions. If that conditions don't occur, $\Psi_{1}(t)$ is treated as a new input signal and the separation process is repeated $k$ times, until some candidate $\Psi_{1 k}(t)$ meets conditions and effectively becomes an IMF, or obeying a tolerance (to/) given by the Eq. (4), defined by Huang et al. (1998), so that the process does not extend indefinitely:

$$
\begin{gathered}
\Psi_{11}(t)=\Psi_{1}(t)-m_{1}(t) \\
\vdots \\
\Psi_{1 k}(t)=\Psi_{1(k-1)}(t)-m_{1(k-1)}(t) ; \\
\sum_{t}\left(\frac{\Psi_{i}(t)-\Psi_{i-1}(t)}{\Psi_{i-1}(t)}\right)^{2}<\text { tol. }
\end{gathered}
$$

When found, the IMF is removed from the data, and from residue are obtained new $n$ IMFs:

$$
\begin{gathered}
r_{1}(t)=X(t)-\Psi_{1}(t) \\
\vdots \\
r_{n}(t)=r_{n-1}(t)-\Psi_{n}(t) .
\end{gathered}
$$

The IMFs taken from data, when added to the residue, restore the original data, thus:

$$
X(t)=\sum_{i=1}^{n} \Psi_{i}(t)+r_{n}(t) .
$$

This property allows the IMFs panels manipulation, so that only remain in the data desired frequency bands, since they have bands of decreasing frequency, according to the order in which they were extracted from the input signal. Each signal has a IMFs finite number, so the decomposition process can't continue indefinitely. The IMFs extraction process ends when the operator defines a maximum number of IMFs to be obtained or when only three extremes remains in the main function, on which it isn't possible to trace envelopes.

\section{SINGULAR VALUE DECOMPOSITION}

The Singular Value Decomposition (SVD) enables any data matrix can be decomposed into a finite array of unitary rank weighted sum. In seismic data, this decomposition can be used in events separation, since the events with increased horizontal correlation are present in the first eigenimages, which are associated with the largest singular values.

Take the $X_{m \times n}$ array of seismic data, in which $m$ is the number of traces and $n$ is the number of samples. Vectors basis of decomposition are the eigenvectors associated covariance matrices $\mathbf{X} \mathbf{X}^{T}$ and $\mathbf{X}^{T} \mathbf{X}$. The singular value decomposition of a rectangular matrix is possible and consists in determining from $X$ two orthogonal matrices, $\mathbf{U}$ and $\mathbf{V}$, and also the singular values matrix $\boldsymbol{\Sigma}$, so that it satisfies the following condition:

$$
\mathbf{X}=\mathbf{U} \boldsymbol{\Sigma} \mathbf{V}^{T},
$$

in which, $\boldsymbol{\Sigma}$ is a rectangular diagonal matrix, of the same $\mathbf{X}$ kind, with the main diagonal containing the singular values, resulting from the positive square roots of eigenvalues associated.

The matrix $\mathbf{X}$ factorization in Eq. (7) form is possible and was algebraically demonstrated by Noble \& Daniel (1977). The SVD may also be represented as a sum of unitary rank matrices, weighted by their respective singular values, i.e.:

$$
\mathbf{X}=\sum_{i=1}^{p} \sigma_{i} \mathbf{u}_{i} \mathbf{v}_{i}^{T}=\sum_{i=1}^{p} \widetilde{\mathbf{X}}_{i},
$$

in which, $\mathbf{u}_{i}$ and $\mathbf{v}_{i}$ are the ith eigenvectors of matrices $\mathbf{U}$ and $\mathbf{V}$, respectively. $\sigma_{i}$ is the ith singular value of matrix $\mathbf{X}$.

The scalar product $\sigma_{i} \mathbf{u}_{i} \mathbf{v}_{i}^{T}=\widetilde{\mathbf{X}}_{i}$ is called the ith eigenimage. Each eigenimage is a unitary rank matrix with same dimensions of matrix $\mathbf{X}$.

\section{APPLICATION METHODOLOGY}

In order to increase the efficiency of noise attenuation in seismic data, we tested the combined performance of these two methods presented, DME and SVD, in a land seismic line from Tacutu Basin and a marine line from Grane oilfield region. The marine data acquisition was done in a shallow water layer, using the $\mathrm{OBC}$ technique (Ocean Bottom Cable), which consists of fixing receivers on the ocean floor.

Among the unwanted events that will be dealing, the Ground Roll is a terrestrial seismic noise related to surface Rayleigh waves. It has a good definition about the predominant frequency content, around $10 \mathrm{~Hz}$ (low frequencies), and has linear spatial arrangement on seismograms. Due to acquisition format and conditions, the Grane Field seismic line is heavily contaminated with 


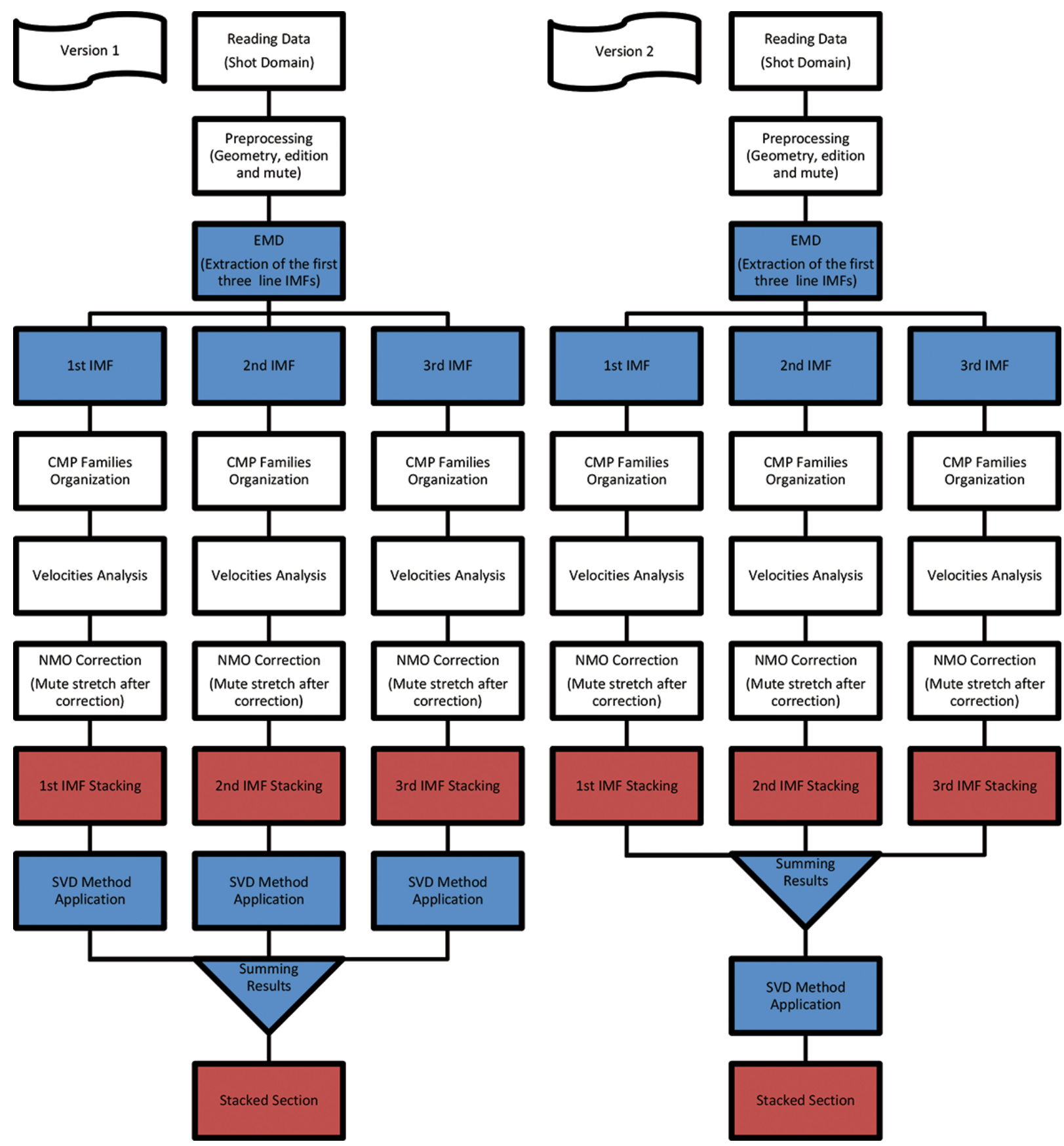

Figure 1 - Processing flowchart of SVD and EMD combined application on both versions presented in this paper to terrestrial Tacutu Basin line.

noise like harmonic modes and head waves. They have a strong scattering in the amplitudes spectrum, hindering the filter operations that use frequency as the key to noise location, however they all have strong linear, preserved almost faithfully, even after NMO correction and stacking. A brief discussion about harmonic modes and head waves noise was made by Landro (2007).
The EMD method can be applied trace to trace at any processing stage. Each data has a finite number of IMFs that can be extracted. Each IMF stores information in a limited frequency band, making it possible to capture and remove some noise in one of these ranges. On the other hand, the SVD method traps a maximum of horizontal coherent information (trace to trace coherency) 
within the first eigenimages. To use it as a filtering method, it is necessary that the data is arranged as to enhance such coherence. Linear noise are sensitive to the SVD method, especially in processing step like after the NMO correction or stacked section, at these stages, interest reflections have high horizontal correlation.

The processing steps have been performed using the free software Seismic Unix (SU), except for the filtering methods DME and SVD, which were implemented in FORTRAN90 language. One of the challenges of joining these versatile and promising method for seismic application is knowing how to combine them, since there is a many ways to do this. The application methodology was modified according to each type of data used, this way of approach allows us to adapt the methods to work with different data and noise characteristics.

\section{RESULTS AND DISCUSSION}

In land seismic line we used the same methodology in different ways. The first version was made applying the EMD method in preprocessed line, each IMF was extracted and individually stacked, and the result of each stacking was applied SVD technique. The second version was very similar to the first, but the SVD technique application was made after the sum of the previously stacked interest IMFs. The processing flowchart of the two versions applied is shown in Figure 1. Both versions were extracted the first three IMFs, responsible for higher frequency components. Even after stacking, reflections demonstrate a strong horizontal correlation, which does not happen with noise, so we chose to use only the first eigenimage. In Figure 2 is made a comparison between the input stacked section and filtered with the proposed methodology. In Figure 3 spectrum is possible to observe a reduction in the amplitude peak in the $10 \mathrm{~Hz}$ frequency, but a portion of these amplitudes remain preserved in the data. An interesting fact observed is the increase in energy amplitudes to frequencies around $30 \mathrm{~Hz}$, the energy that is captured with this frequency content is associated with interest events.

The processing marine line flowchart is shown in Figure 4. The association procedure that generated better results began with the application of SVD technique in CMP family chosen after NMO correction, we sum only the first eigenimage. This procedure preserves the relative amplitude, horizontal events character and attenuates noise that is associated with other eigenimages (Porsani et al., 2009). The Figure 5 presents seismograms with the steps of applying filtering. In original CMP it is possible to distinguish clearly determined the presence of unwanted linear noise. In the Figure 6 frequency spectrum we presented the Figure 5 seismograms frequency content.

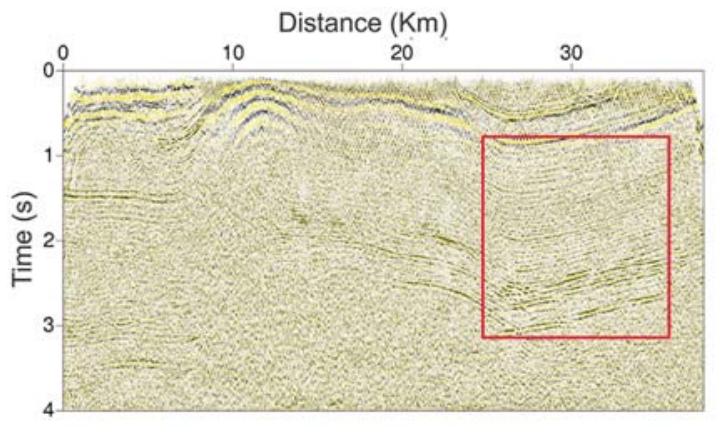

(a)

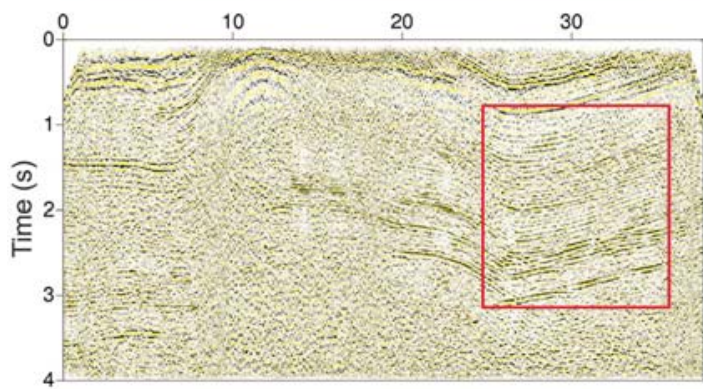

(b)

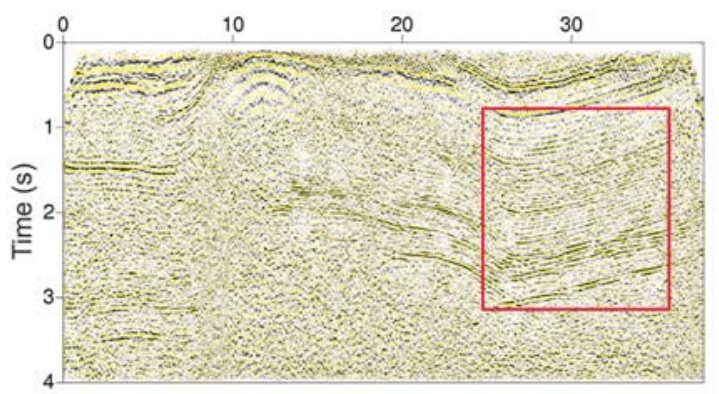

(c)

Figure 2 - Comparison between the input section stacking (a), SVD filtering in each of the first three already stacked IMFs (b) and SVD on the sum of the first IMFs already stacked (c). Highlighting areas with a gain related to interest reflections amplitude.

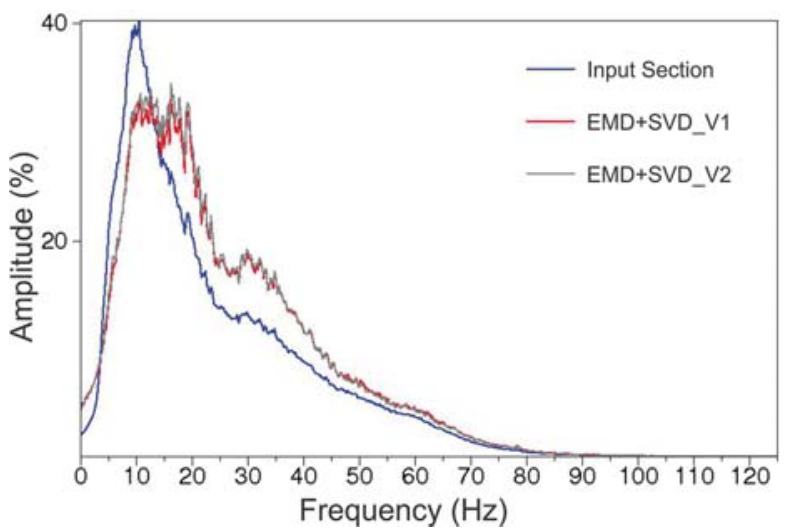

Figure 3 - Amplitudes spectrum from Figure 2 stacked sections. Input section (blue), SVD filtering in each of the first IMFs already stacked (red) and SVD in the sum of first three IMFs already stacked (gray).

The second step in the methodology developed to marine line filtering is EMD method application in eigenimage obtained by the 


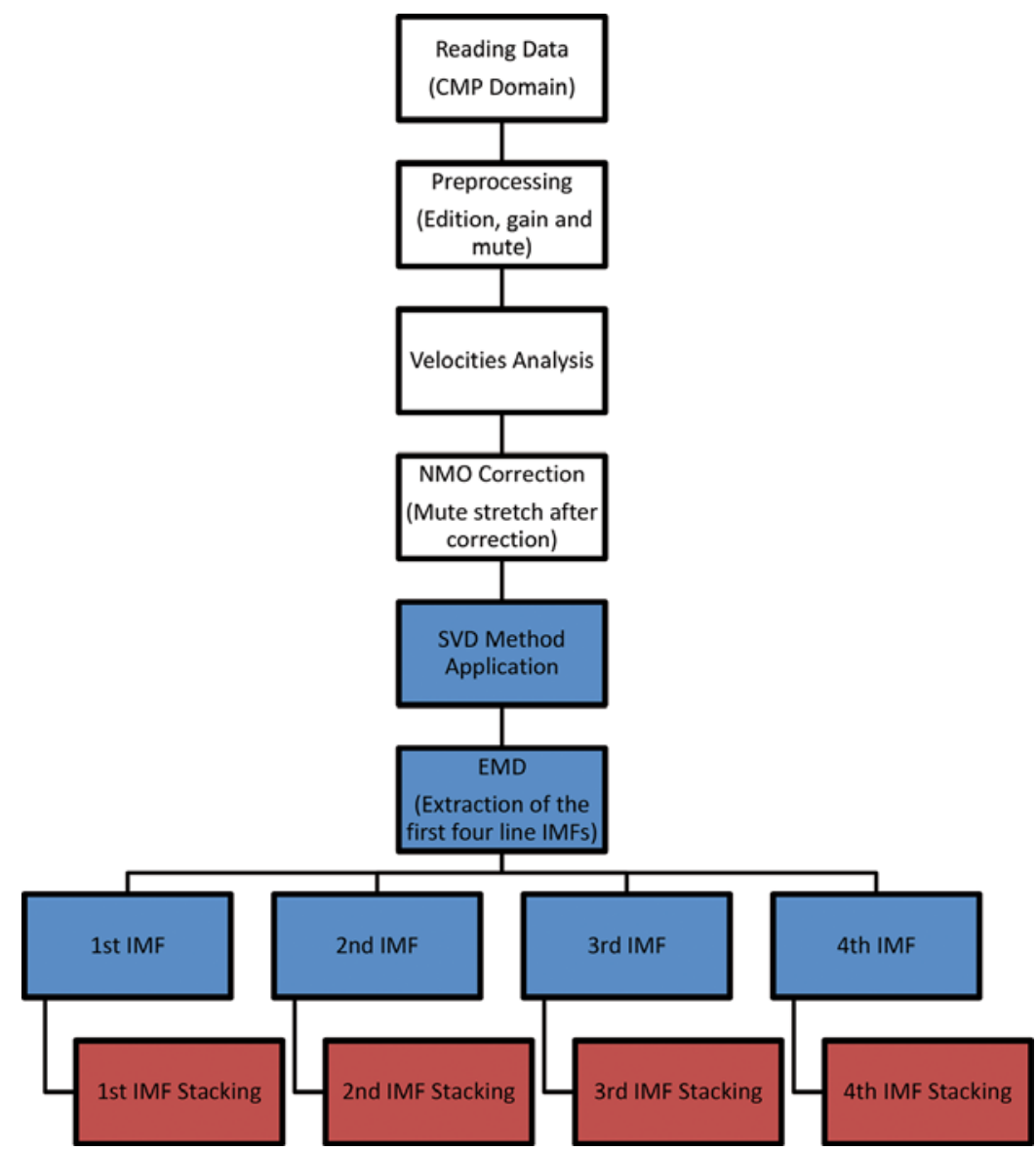

Figure 4 - Processing flowchart of SVD and EMD combined application on marine line from Grane Field.

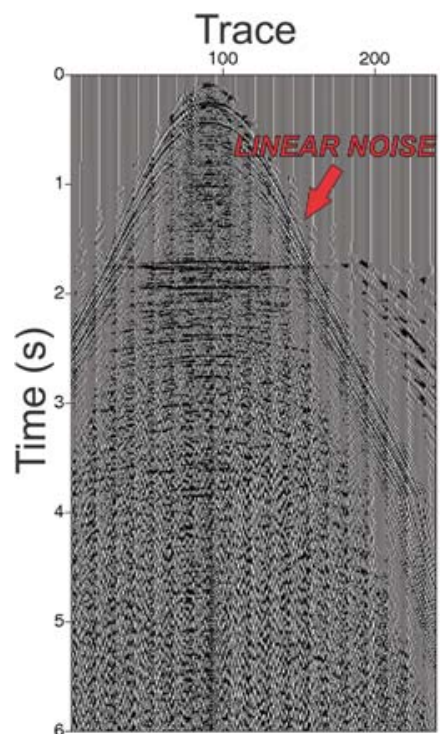

(a)

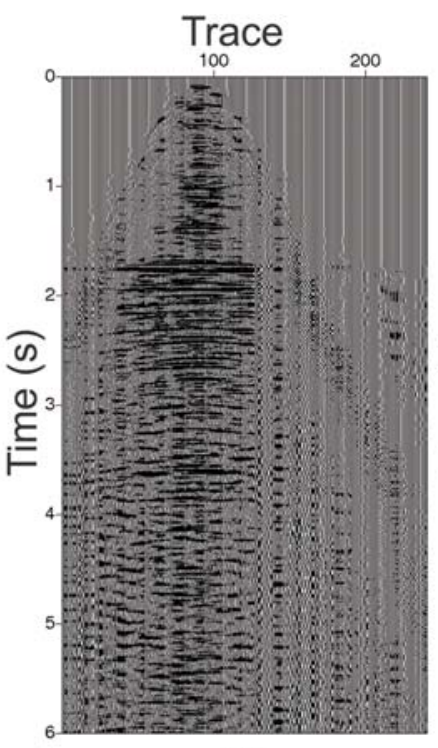

(b)

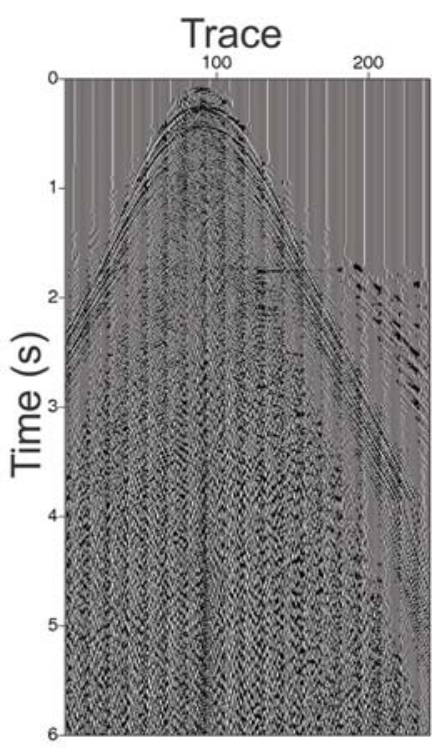

(c)

Figure 5 - CMP 300 from the Grane Field marine line. Input (a), SVD filtering (b) and residue between (a) and (b) presented in (c), all NMO corrected. Highlighting the linear noise type head waves and harmonic modes. 


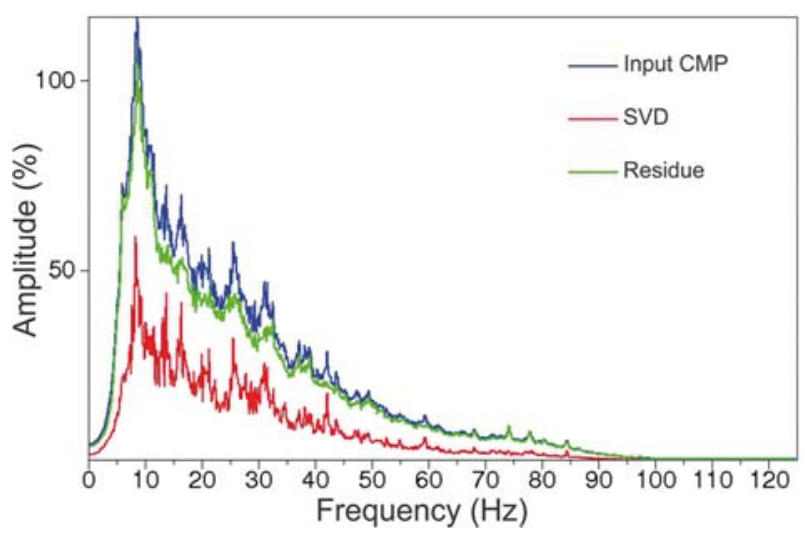

Figure 6 - Amplitudes spectrum from Figure 5 CMPs. Input (blue), after SVD filtering (red) and the residue (green).

singular value decomposition, they were then extracted the first four line IMFs. The stacking of each IMF is shown in Figure 7. The first IMF carries a high frequency noise component, but also carries a substantial amount of thinner reflectors information at the shallow and deep part of the area. In this case it is more difficult to use frequency filters (such as EMD), hence the joint implementation SVD method importance. The definition about the first IMF use, as well as all others, depend on the interest target. The four stacked IMFs were summed, so that we could restore the input data with less noise. The comparison between the input stacked data and the filtered data with EMD and SVD method is shown in Figure 8.

\section{CONCLUSIONS}

In the present work we developed a new approach in noise seismic reflection data treatment, from known and appreciated techniques in literature. By analyzing the behavior of common noises in different types of data, we combine the methods of Empirical Mode Decomposition (EMD) and the Singular Value Decomposition (SVD) trying to get out of its main features, the ultimate goal was to locate and extract undesirable events, aiding seismic sections processing and interpretation.

In the seismic land of Tacutu basin we reached two relatively simple application alternatives, that have generated good results in ground roll attenuation, without significant interest signal loss. From the used techniques, it was possible to capture much of the ground roll noise in last IMFs (low frequency components), eliminating them the data. To be a linear event, the SVD method was able to locate and retain it, in the last eigenimages, eliminating noise residues still present in the stacked section.

The results of the SVD and DME combined application in Grane marine data was interesting, because we can, from method- ology used, mitigate the noise head waves and harmonic modes. The seismic section decomposition in IMFs bands enabled a better definition of high frequency reflectors in depth in the first IMFs, this effect becomes very interesting because, in depth, the seismic reflection has difficulty in solving lithological thinner layers, responsible for such reflectors. During testing, the processing time was monitored so that there were no distortions, which would make it impossible the practical methods use. In any applications were observed those excess.

\section{ACKNOWLEDGEMENTS}

The authors wish to express their gratitude to FINEP, FAPESB, ANP (Projeto Campo Escola-UFBA) and CNPq-INCT-GP for financial support. The authors also thank Petrobras, Landmark by cooperation agreements that allow the use of the licenses of softwares of processing granted to LAGEP-CPGG-UFBA. The sponsors of the Grane project (StatoilHydro, Petoro, ExxonMobil and ConocoPhillips), by giving in data from the Grane Field. The geophysicist Dr. Martin Landro, for support and help in getting that data.

\section{REFERENCES}

ALVES FM, SILVA MG \& PORSANI MJ. 2011. Filtragem de Eventos Lineares utilizando os Métodos da Transformada Radial e Decomposição em Modos Empíricos. In: 12- Congresso Internacional da Sociedade Brasileira de Geofísica, Rio de Janeiro-RJ, Brazil. CD-ROM.

BEKARA M \& BAAN MV. 2009. Random and coherent noise attenuation by empirical mode decomposition. Geophysics, 74: V89-98.

CARDOSO CAR. 2010. Atenuação do Ground roll utilizando Filtragem SVD. Undergraduate Final Project, Universidade Federal da Bahia, Salvador-BA, Brazil. 

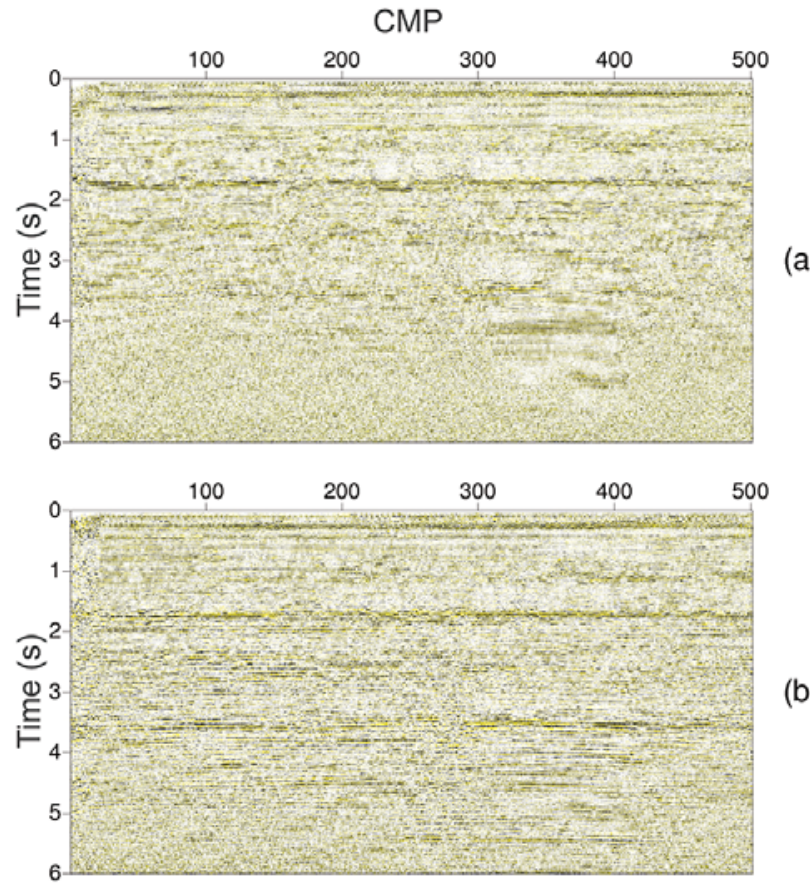

(a)

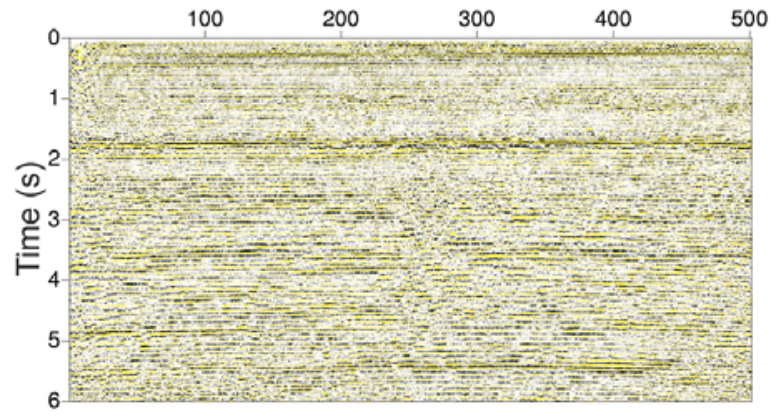

(c)

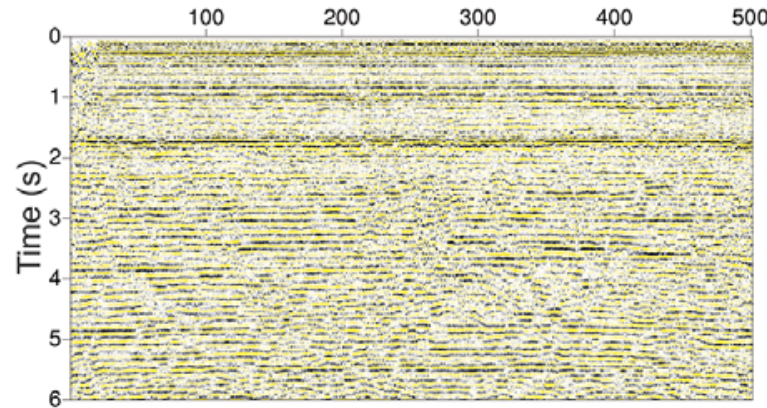

(d)

Figure 7 - Stacked seismic section of the first IMF (a), second (b), third (c) and fourth (d), extracted in the time domain after applying SVD filtering.

FERREIRA LES. 2010. Aplicação do Método de Decomposição em Modos Empíricos na atenuação do Ruído de Rolamento em Dados Sísmicos. Master Dissertation, Universidade Federal da Bahia, SalvadorBA, Brazil.

FREIRE SLM. 1986. Aplicações do Método de Decomposição em Valores Singulares no Processamento de Dados Sísmicos. Doctorate Thesis,
CPGG-UFBA, Salvador-BA, Brazil.

HUANG NE, SHEN Z, LONG SR, WU MC, SHHH HH, ZHENG Q, YEN NC, TUNG CC \& LIU HH. 1998. The empirical mode decomposition and the Hilbert spectrum for nonlinear and non-stationary time series. The Royal Society London, 454: 903-995. 


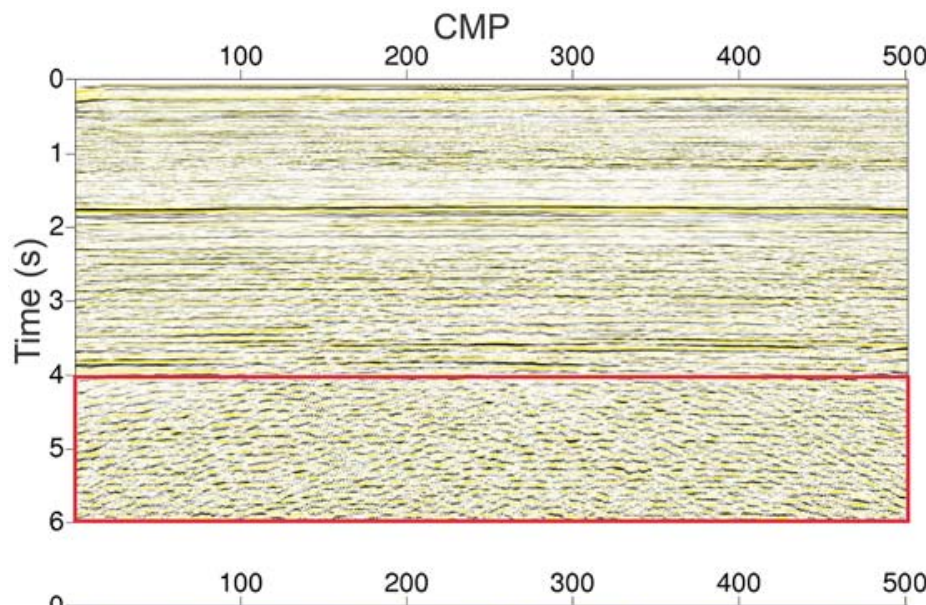

(a)

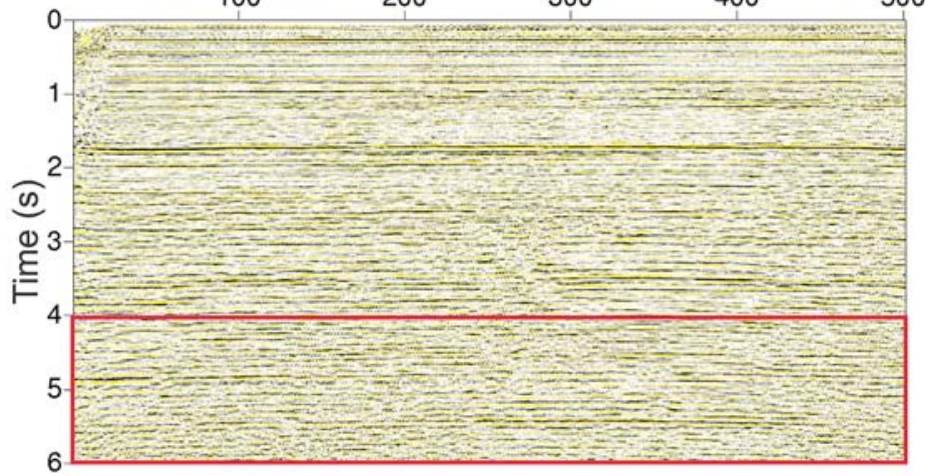

(b)

Figure 8 - Comparison between the input stacked data (a) and the filtered data with EMD and SVD method (b). Highlighting areas with a gain related to interest reflections amplitude.

LANDRO M. 2007. Attenuation of seismic water-column noise, tested on seismic data from Grane Field. Geophysics, 72: V87-V95.

LIMA RR. 2014. Atenuação do ground ro// utilizando filtragem adaptativa SVD no domínio da frequência e deconvolução iterativa com norma Lp. Undergraduate Final Project, Universidade Federal da Bahia, Salvador-BA, Brazil.

MELO PEM, PORSANI MJ \& SILVA MG. 2009. Ground roll attenuation using a 2D time derivative filter. Geophys. Prospect, 57: 343-353.

NOBLE B \& DANIEL JW. 1977. Appllied linear algebra. Prentice-Hall Englewood Clifs, New Jersey.

PORSANI MJ, MELO PEM, SILVA MG \& URSIN B. 2009. Filtragem do ground rol/ utilizando SVD. In: 110 Congresso Internacional da Sociedade Brasileira de Geofísica, Salvador-BA, Brazil. CD-ROM.
SÁ AJ. 2013. Aplicação do método de Decomposição em Modos Empíricos no Processamento de Dados Sísmicos Marítimos. Master Dissertation, Universidade Federal da Bahia, Salvador-BA, Brazil.

SHEPARD D. 1968. A two-dimensional interpolation for irregularlyspaced data. In: Proceedings of the 23rd ACM National Conference, 517-524.

TELFORD WM, GELDART LP \& SHERIFFRE. 1990. Applied Geophysics. Cambridge University Press, Cambridge, England.

YILMAZ 0. 2001. Seismic Data Analysis. Society of Exploration Geophysicists, Tulsa, U.S.A. 526 pp.

ZEGADI A \& ZEGADI KK. 2009. Coherent and random noise attenuation using the intrinsic timescale decomposition. In: SEG Houston 2009 International Exposition and Annual Meeting.

Recebido em 10 agosto, 2015 / Aceito em 22 novembro, 2016

Received on August 10, 2015 / Accepted on November 22, 2016 